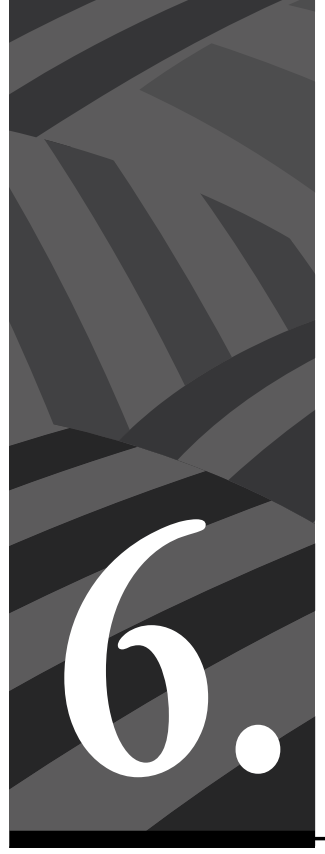

El difícil camino de la paz.

Avatares de la implementación de los acuerdos FARC-EP y

Gobierno colombiano en Icononzo (Tolima) 


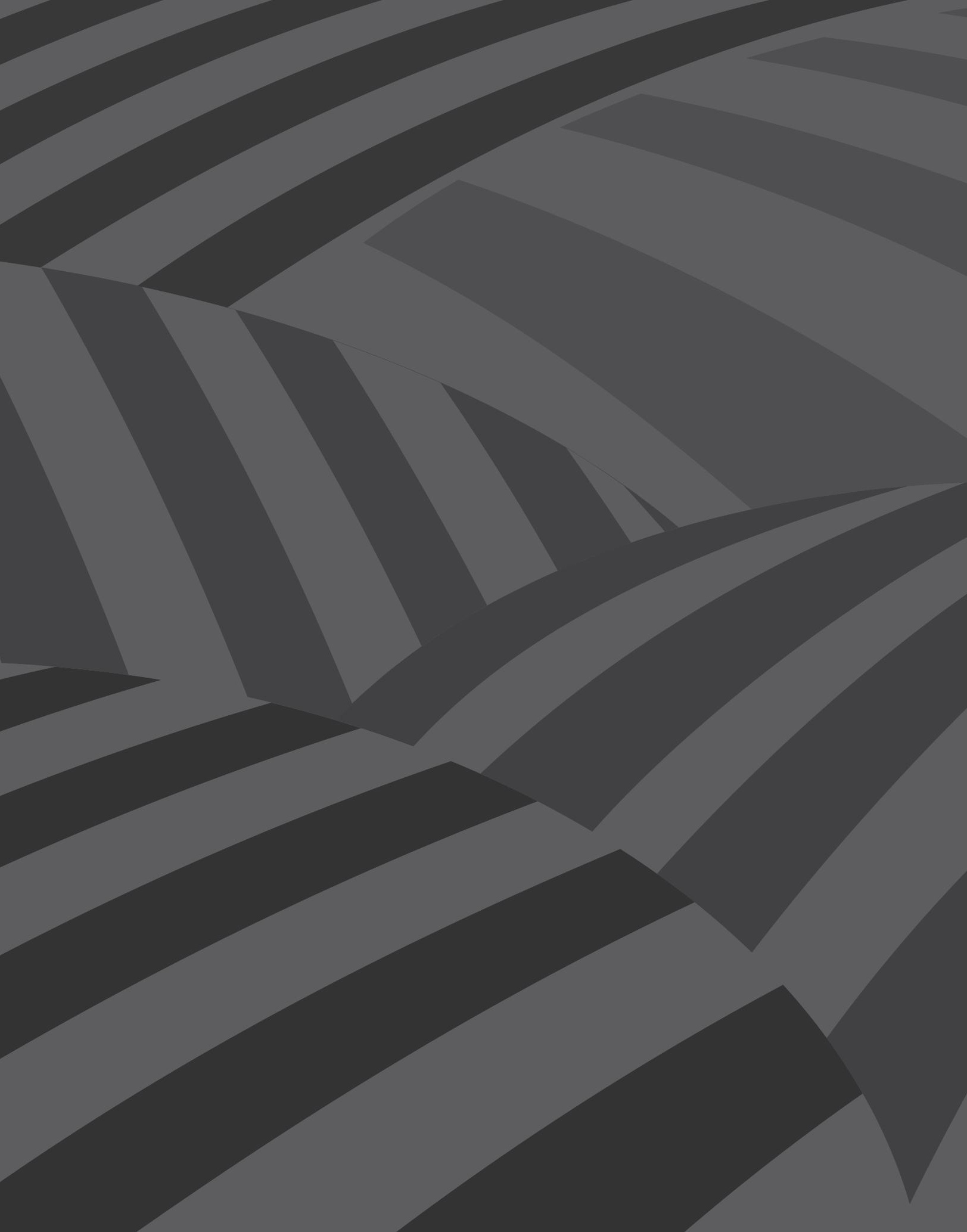




\section{El difícil camino de la paz. Avatares de la implementación de los acuerdos FARC-EP y Gobierno colombiano en Icononzo (Tolima)}

Por Wilson Pabón*

DOI: https://doi.org/10.54118/controver.vi217.1244

Resumen: Con la firma del Acuerdo Final para la Terminación del Conflicto y la Construcción de una Paz Estable y Duradera entre el Gobierno colombiano y la guerrilla de las FARC-EP, en noviembre de 2016, se establecieron una serie de acuerdos sobre diferentes puntos, entre ellos el establecimiento de unas zonas de concentración en varias regiones del país, en las cuales los excombatientes harían su tránsito a la vida civil. Para entender las dinámicas de lo sucedido en este importante proceso, se analiza el caso del espacio territorial de capacitación y reincorporación (ETCR) Antonio Nariño, en Icononzo (Tolima), el más cercano a Bogotá. Luego de un trabajo de campo de dos años, en el que se realizaron entrevistas con los habitantes de la región de Sumapaz, lo mismo que con quienes están alrededor del proceso, se plantea una perspectiva de análisis de corte etnográfico sobre el tema. Esto como paradigma de lo sucedido en el país, concretamente en el Sumapaz, una región en la cual tanto la guerra como la paz se han vivido desde hace más de setenta años, buscando aportar a la comprensión del conflicto armado interno en Colombia.

Palabras clave: Colombia, Acuerdo de Paz, conflicto armado interno, Gobierno/FARC-EP, Sumapaz.

\section{The Difficult Course to Peace. Avatars of the Implementation of the Farc - Colombian Government Peace Accords in Icononzo (Tolima)}

Abstract: With the signing of the Peace Accords between the Colombian government and the Farc-EP guerrilla in 2016, concentration zones were established in various regions of the country, in which ex-combatants would make their transition to civilian life. To understand the dynamics

* Historiador por la Universidad Nacional de Colombia; magíster en Ciencias Sociales de las Religiones por la École Pratique Des Hautes Études, Francia; candidato a doctor en Antropología y Sociología, Université Paris VII-Denis Diderot, Francia. Actualmente es docente-investigador de tiempo completo de la Facultad de Comunicación Social-Periodismo de la Universidad Externado de Colombia. Correo: wilsonpq@hotmail.com - ORCID: 0000-0002-3824-7936 
of what happened in this important process, the case of the ETCR Antonio Nariño in Icononzo (Tolima), the closest to Bogotá, is analyzed. As part of a two-year fieldwork, in which I conducted multiple interviews with the habitants of the Sumapaz region, as well as with those around the process, I propose a ethnographical analysis to this question. Such approach is proposed as a case study to understand the challenges provoked with the implementation of the peace accords in Colombia. In so doing, this chapter seeks to contribute to the understanding the internal armed conflict in this country while contextualizing such analysis in a region in which both war and peace have been lived for more than seventy years.

Keywords: Colombia, Peace Accords, Internal Armed Conflict, Government-Farc, Sumapaz.

Cómo citar este artículo: Pabón, Wilson (2021). El difícil camino de la paz. Avatares de la implementación de los acuerdos Farc-EP y gobierno colombiano en Icononzo (Tolima). Revista Controversia, 217, 221-255.

\section{Introducción}

El domingo 30 de abril de 2017, unos jóvenes amanecieron dormidos en la plaza principal de Icononzo junto a botellas desocupadas de aguardiente y latas de cerveza. Bebieron toda la noche y sus motocicletas de alto cilindraje sonaron estruendosamente durante varias horas desvelando a los vecinos. Como la plaza es inclinada y cuenta con escalinatas, estas sirvieron para que ellos emularan acrobacias de motocross. Se trataba de excombatientes de las FARC-EP, quienes aprovechando el nuevo momento que vivían luego de la firma del Acuerdo Final para la Terminación del Conflicto y la Construcción de una Paz Estable y Duradera (en adelante Acuerdo de Paz o Acuerdo) con el Gobierno colombiano, en 2016, expresaban de esta forma la libertad en la que se sentían. Esto no cayó bien entre los icononzunos, a tal punto que algunos se refirieron a ellos como delincuentes borrachos, otros como peligrosos desconocidos, pero también hubo quienes pidieron comprensión y llamaron al entendimiento de sus razones de actuar. 
Este es un pequeño reflejo de lo que se vive en el municipio y en la región de Sumapaz en relación con el Acuerdo de Paz, esfuerzo que divide a los nacionales entre los que están a favor y los que se manifiestan en contra, tal cual como el país polarizado que se expresó entre el sí y el No en el plebiscito para refrendarlo, entre el guerrillero y el "paraco", entre el liberal y el conservador, en lo que parece que solo se vieran dos caras de la moneda, como si en la gradación entre negro y blanco no hubiera nada de grises. De esto se aprovecharon los políticos y lo replicaron los medios de comunicación. Es Colombia en pequeño, pero viviendo junto al excombatiente; es, en definitiva, la paz real.

La región de Sumapaz ha sido considerada históricamente un bastión de movimientos campesinos de lucha por la tierra. Allí surgieron partidos políticos como el Partido Agrario Nacional (PAN) de Erasmo Valencia y Juan de la Cruz Varela, y tuvo mucha fuerza el Partido Comunista de Colombia (PCC). Posteriormente, hubo la presencia de grupos guerrilleros liberales durante los años cincuenta, y del Frente Democrático de Liberación Nacional, antecesor de las FARC. Además, es considerada un “corredor natural de movilidad” dentro de las dinámicas del conflicto armado interno de Colombia, puesto que es un área ubicada en el centro del país, que conecta la región de los Llanos Orientales y el suroriente con la capital Bogotá (Londoño, 2012), lo que explica su importancia estratégica y económica.

Como consecuencia de la firma del Acuerdo de Paz entre el Gobierno colombiano y la guerrilla de las FARC-EP en el año 2016, se decidió ubicar en lugares específicos de la geografía nacional a los guerrilleros que entregaron sus armas. Allí tendrían un acompañamiento por parte de los organismos internacionales y de entidades estatales para su tránsito a la vida civil. Para validar las negociaciones, el presidente Juan Manuel Santos decidió acudir al elector primario, realizando el 2 de octubre de 2016 un plebiscito en el que se les preguntó a los colombianos si estaban de acuerdo o no con lo pactado. Por un pequeño margen $(0,45 \%)$ 
el No fue el ganador, y eso generó que se dilatara la puesta de un sello final al conflicto entre este grupo y el Gobierno colombiano, hasta que se realizaran algunas reformas puntuales.

En el punto 3.1.4. "Adaptación de los dispositivos en el terreno y zonas”, quedó definido el establecimiento de 20 zonas veredales transitorias de normalización (ZVTN), donde se ubicarían los exguerrilleros desmovilizados en su tránsito a la vida civil. La guerrilla de las FARC-EP había solicitado la ubicación de una de estas en la zona rural del municipio de Villarrica (Tolima), puesto que lo consideraban uno de sus reductos históricos. No obstante, en este lugar un gran porcentaje de los votantes del plebiscito se inclinó por no estar de acuerdo, puesto que, como mencionó el concejal Manuel Enrique Moreno: “Aquí nació la revolución, pero no queremos que aquí siga”, a lo que se sumaban múltiples problemas de infraestructura (Vélez, 2016).

En Sumapaz la única población que apoyó con su voto los acuerdos fue la de Icononzo, igualmente con resultados muy apretados en el plebiscito por la paz: $52,87 \%$ por el sí y $47,12 \%$ por el No, razón por la cual fue allí donde se estableció en 2016 la ZVTN más cercana a Bogotá, lo que les permite dar cuenta de la forma en que la llegada de los exguerrilleros transformó la vida en esta parte del país, como consecuencia de una apuesta por el fin de la guerra de forma concertada.

El trabajo de campo realizado en este municipio entre el 2017 y 2019 incluyó visitas a la ZVTN donde estaban concentrados los exguerrilleros, entrevistas con habitantes de Icononzo y de la región de Sumapaz, y encuentros con grupos de pobladores, alrededor de la implementación de los acuerdos del Acuerdo de Paz, lo mismo que sobre la guerra y la pacificación que se han dado allí desde la década de los años cuarenta. El presente escrito es un ensayo de corte etnográfico, en el cual se resalta también un proceso de historia reciente o de historia del tiempo actual. En este sentido, la principal fuente es la oral, contrastada con la 
poca publicación existente, como algunas tesis y documentos producidos hasta el momento, de una historia inacabada.

Se presenta así una visión del difícil proceso de implementación del Acuerdo de Paz entre las FARC-EP y el Gobierno colombiano, lo que servirá para comprender, desde el municipio de Icononzo, esta dinámica como paradigma de lo sucedido hasta el momento en Colombia. La primera parte da cuenta de las posiciones de los habitantes de Sumapaz frente a la paz. En la segunda parte se evidencian las dinámicas sociales de la cotidianidad a través de la convivencia de los pobladores con nuevos sujetos, como los exguerrilleros; con la presencia de nuevas instituciones del Estado en la zona e incluso de organismos internacionales como la ONU. Posteriormente, se expondrán las acciones concretas del Gobierno en cuanto a la implementación del Acuerdo. Y, finalmente, se ejemplifica la manera en que los excombatientes buscan su reintegración social y económica a través de los proyectos productivos. Todo esto para entender cuáles han sido las dificultades para el logro de la paz en el país, con una perspectiva de media y larga duración, en la que la guerra y no la paz siempre se ha concebido como la mejor salida al conflicto armado interno en Colombia.

\section{La paz en Icononzo}

El municipio de Icononzo, particularmente, no es reconocido como uno de los más violentos de Colombia, pero las diversas manifestaciones de esta índole que han azotado al país desde los años cuarenta del siglo pasado han tenido expresiones en su territorio, dejando su estela de víctimas y recuerdos de muerte. De hecho, en una indagación sencilla entre los habitantes de Bogotá, muchos dijeron nunca haber escuchado mencionar el nombre de Icononzo, a pesar de la notoriedad que podría haber logrado por tener en su zona rural una de las ZVTN donde hay concentración de excombatientes desde 2016, como ha sucedido con otros de estos espacios a nivel nacional. 
La vida transcurría normalmente en el pueblo, uno de los más habitados de la parte montañosa al oriente del departamento de Tolima (10 057 hab.). Sin embargo, a raíz de la última contienda electoral, al bullicio tradicional de las plazas centrales de estos asentamientos urbanos, se sumaban ahora las calles adornadas con pancartas o pasacalles de los candidatos a la presidencia en 2018, e Icononzo no fue la excepción. En la calle principal, específicamente en la salida hacia el municipio contiguo de Pandi, colgaban pasacalles con fondo blanco que anunciaban: "[Gustavo] Petro Presidente", y en algunos negocios de la misma cuadra, para hacer contrapeso, en afiches puestos en las paredes se veía la imagen del candidato del "uribismo", hoy presidente, con las manos extendidas en señal de acogimiento y amistad, emulando una de las expresiones de Jesús, sobre fondo azul claro, con la frase: “[Iván] Duque Presidente”. Las opciones estaban claras: cada alternativa representaba el debate que enfrentaba el país para las elecciones, Duque a las fuerzas que se opusieron persistentemente al proceso de negociación con las FARC-EP, y Petro la continuación del proyecto de paz con las guerrillas.

En la zona de concentración de los excombatientes este debate acalorado no solo lo podían ver por televisión, sino que los preocupaba porque los directamente implicados eran ellos mismos, pues se encontraban en el dilema de apegarse a que el Gobierno mantuviera las garantías de la paz y el respeto por los puntos acordados en el Acuerdo de Paz firmado, o verse obligados nuevamente a tomar las armas y "devolverse para el monte”. En principio, si Gustavo Petro lograba la presidencia, los acuerdos continuarían su camino, mientras que si Iván Duque llegaba al poder lo primero que haría sería llamar a una revisión de estos en el Congreso. Las cartas estaban echadas: los guerrilleros habían entregado las armas, y la única opción que tenían era la de esperar una decisión democrática en este nuevo juego político en el que participaban electoralmente, muchos ejerciendo su derecho al voto por primera vez en 
su vida. En Icononzo las elecciones favorecieron a Iván Duque, con el $56,30 \%$ frente a Gustavo Petro, quien obtuvo el $41,08 \%$.

El 15 de agosto de 2017 las ZVTN pasaron a llamarse espacios territoriales de capacitación y reincorporación (ETCR). Para abril de 2019, según la Agencia para la Reincorporación y la Normalización, 2935 excombatientes se encontraban concentrados en ellos. A Icononzo llegaría el $9 \%$ del total de los desmovilizados de las FARC-EP. La gran mayoría se esparcieron por el país, pues retornaron a sus regiones de origen o de localización de su familia y se vincularon a la vida civil de la forma en que pudieron, pensando que debían buscar oportunidades de manera más individual que colectiva, dada la evidencia de la mala voluntad del Gobierno Nacional respecto al cumplimiento de algunos puntos de lo pactado en el Acuerdo de Paz y las pocas garantías para su reinserción e incluso para salvaguardar su propia vida (El Espectador, 2019).

La ZVTN ubicada en la vereda La Fila, de Icononzo, se conoce en el país por ser la que más ha mantenido un número elevado de excombatientes que se reincorporaron desde el principio de los Acuerdos. Según ellos mismos, para principios de este año (2021) vivían allí todavía alrededor de 300 con sus familias, muchos provenientes de otras regiones. Cabe aclarar que este espacio fue tomado en arriendo a Luis Zorro Pineda, hacendado de la región, quien en un principio estuvo en contra de los diálogos de paz, pero al parecer ahora apoya el proceso, ya que incluso hizo parte de la campaña a la Alcaldía de Luz Mery López, "Valentina Beltrán", candidata del Partido FARC en las elecciones de 2019. En agosto de 2020 la Agencia Nacional de Tierras le compró a Zorro las 22 hectáreas del ya denominado ETCR, transacción hecha por un valor de 491 millones de pesos (El Nuevo Día, 2020).

Algunos exguerrilleros entrevistados manifestaron que en los primeros días, luego de la firma del Acuerdo de Paz, el diálogo entre ellos y los representantes de la fuerza pública colombiana parecía cordial, 
obviamente, con contadas excepciones. En Icononzo se llegó, incluso, a realizar campeonatos de microfútbol en los cuales compitieron amistosamente el equipo de excombatientes de las FARC y los equipos de la Policía o del Ejército. Sin embargo, desde que llegó al poder Iván Duque se nombraron nuevos oficiales y suboficiales, y llegaron a la zona soldados que, al decir de los pobladores, mostraban un rechazo a los acuerdos y a la presencia de los exguerrilleros en el casco urbano; además, los caracterizaba el haber estado en zonas "calientes", en donde los combates con la guerrilla les habían generado heridas de guerra o pérdida de compañeros, violencia que los marcó y que manifestaban cuando se referían al hecho de estar al lado de sus "enemigos". Los excombatientes continuaron con sus equipos, pero ahora participando en torneos locales o departamentales. Al acabarse estos duelos amistosos que distensionaban el ambiente se truncó esta simbólica forma de reconciliación.

En atención a ello, para facilitar el control y vigilancia de los ETCR y los seis campamentos por parte del mecanismo tripartido de las Naciones Unidas, en el gobierno del presidente Santos se acordó que el personal del Ejército asignado al dispositivo de seguridad, patrullaje y control territorial utilizaría unos uniformes distintos, para que los guerrilleros se sintieran más cómodos con su presencia, y que los soldados de la zona portarían sus armas a la espalda, y no terciadas en frente a modo de combate, como hacían regularmente. El nuevo uniforme militar transitorio se denominó "patriota” y consistió en un camuflado con un patrón pixelado de color desértico. Con la Administración Duque los soldados volvieron al camuflado de la selva, que combina el patrón pixelado con una textura de escamas, que los ayuda al mimetismo (Fuerzas Militares, 2016) y cargan ahora sus armas preparadas para los enfrentamientos, es decir, están nuevamente listos para la guerra.

En 2018, durante unas fiestas populares en la vereda Cuba, del municipio de Icononzo, fue posible hablar con unos jóvenes excombatientes 
que acababan de jugar un campeonato de microfútbol como parte de las festividades. En la celebración de la noche llegaron sudorosos, con sus uniformes deportivos sucios; los esperaban sus compañeras e hijos. Los nombres de los equipos de los que hacían parte no hacían ninguna referencia a su pasado de combatientes ni a los líderes guerrilleros, con lo cual buscaban marcar que su inserción a la vida civil se daba completamente. Luego del deporte llegó el alcohol, las botellas de cerveza y aguardiente llenaron las mesas, y muy al fondo se escuchaban los gritos de apostadores en las peleas de gallos. La música tradicional levantó a las parejas de sus sillas y comenzó el baile, mientras otros asistentes disfrutaron solo escuchándola. Fue el momento propicio para hablar tranquilamente con estos sujetos que, de no ser reconocidos por los lugareños como exguerrilleros, pasarían como simples campesinos del lugar.

Así se supo que muchos de ellos temen anunciar que viven en el ETCR Antonio Nariño, sobre todo las jóvenes mujeres que cargan bebés en sus brazos. Luego de la firma del Acuerdo de Paz se dio en la guerrillerada femenina lo que se denominó baby boom, ya que estas mujeres que habían sido obligadas a planificar, sentían ahora la tranquilidad de quedar embarazadas y proyectar una familia (Cosoy, 2017). Noviazgos vividos a escondidas salían a flote y se manifestaban con nuevos hijos. Esto fue retratado por la fotógrafa francoespañola Catalina MartinChico en 2017, quien visitó varios ETCR donde evidenció la presencia de mujeres embarazadas y recién nacidos, a tal punto que afirmó: "El paisaje se había transformado totalmente. Las armas habían desaparecido y habían quedado sustituidas por bebés.” (Vicente, 2018, párr. 2).

Los hombres fueron más tranquilos hablando de su pasado. Tienen entre 18 y 25 años, vivieron los horrores de la violencia desde muy pequeños, y casi todos solo conocen el ejercicio de la guerra. En algunos las cicatrices los delatan, pero las muestran con orgullo y rememoran cómo las obtuvieron. El alcohol que fluye por su sangre ayuda a que hablen más tranquilamente, y ante la pregunta de qué va a pasar con 
ellos si los siguen matando uno a uno, la respuesta es contundente: ya entregaron las armas, le apostaron al proceso, pero conseguirlas es fácil, lo hacían en el pasado, se las van quitando a los policías en los pueblos en ataques que saben organizar muy bien, y de a poco se van rearmando. Pero no lo van a hacer todavía, la esperanza de un país distinto, del respeto por la paz, de un mejor futuro ya con hijos y familia, los inspira a continuar con su nueva vida sin guerra.

Sin embargo, existe un grave problema: desde el gobierno del presidente Juan Manuel Santos, luego de la firma del Acuerdo con las FARC-EP, el asesinato sistemático de líderes sociales se volvió frecuente en todo el país. Ahora se escuchan las noticias de hombres armados que se movilizan en motocicletas y que, de repente, asesinan a representantes de grupos políticos o agremiaciones que defienden los intereses de sus comunidades, lo que se convirtió en una preocupación latente. El periódico El Espectador, el 14 de junio de 2020, en cuatro páginas a modo de portada con el titular "No los olvidemos", publicó la lista de los 442 líderes sociales asesinados entre el 24 de noviembre de 2016 y el 30 de marzo de 2020, buscando llamar la atención de la sociedad colombiana sobre las dimensiones de tales crímenes.

A estos líderes sociales que son asesinados de forma recurrente en el país, y como una estrategia de guerra desde hace muchas décadas, se suman desde el 2016 los excombatientes. Según la Jurisdicción Especial para la Paz (JEP), para abril de 2021 ya habían sido asesinados en todo el país 276 miembros de la guerrilla de las FARC-EP que entregaron sus armas.

A pesar de que en la región de Sumapaz el Batallón de Infantería N. ${ }^{\circ}$ 39, adscrito a la Decimotercera Brigada, conforma un anillo de seguridad alrededor del ETCR Antonio Nariño, la respuesta en materia de seguridad por parte de militares y policías departamentales parece precaria. Esto lo denunció la Defensoría del Pueblo en agosto de 2017, en una alerta temprana en la que advierte que tanto la topografía como la poca 
presencia estatal en la zona, "podría representar una importante vulnerabilidad institucional en cuanto a la prevención de la consumación de las amenazas que se han registrado en la región”.

\section{MARCHA POR LA VIDA Y DEFENSA DE LOS LÍDERES SOCIALES ICONONZO, 26 DE JULIO DE 2019}

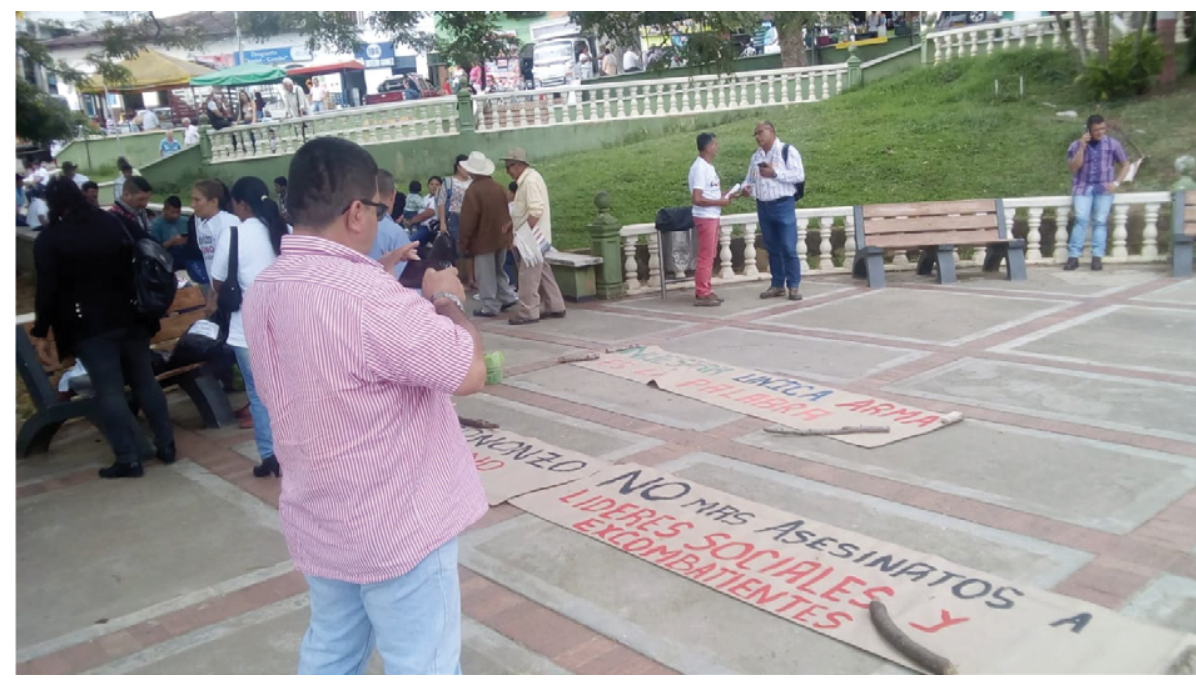

Foto: Jorge Ortegón.

El gran inconveniente para la continuación de la paz es el temor de los excombatientes por su seguridad y por su vida. En algunas discusiones con varios de ellos expresaron saber que esto podía ocurrir, pues sus líderes se lo advirtieron. Llegaron incluso a mencionar que al comienzo confiaron en que seguramente el número de bajas sería menor al que registraban cuando combatían contra el Estado, pero que, desafortunadamente, las cifras de sus compañeros muertos seguían en aumento, lo que les genera mucha preocupación.

\section{Del cambuche al hogar}


La gran mayoría de los excombatientes que viven en el ETCR de la vereda La Fila provienen de los Llanos del Yarí, departamento de Meta. Llegaron a Icononzo luego de varios días de viaje, entre trochas y ríos, escoltados por funcionarios de la ONU. Lograr un espacio aquí no fue nada sencillo, pues había que hacerse a un terreno que los acogiera, que no podía estar cerca del pueblo por seguridad, y tampoco tan lejos para mantener cierto control estatal. El territorio destinado para ubicar a los excombatientes los pobladores de Icononzo lo llaman "el pequeño Chocó”, ya que la lluvia es constante y la selva algo tupida.

Icononzo es conocido como "El balcón del oriente del Tolima” porque desde allí se divisan Fusagasugá, Chinauta y la carretera que comunica a Bogotá con el suroccidente del país. Tiene los tres climas del trópico: en la parte baja, en límites con Melgar, hace mucho calor; donde está ubicado el pueblo, es un clima medio o templado; y subiendo la montaña es cada vez más frío, y es aquí donde fueron ubicados los excombatientes. Es una zona donde no había acueducto ni alcantarillado, y las vías de acceso eran bastante precarias. Las cosas no han cambiado mucho debido a que los dineros destinados al acondicionamiento de estos lugares, y que hacían parte del Acuerdo, han llegado a cuentagotas.

En diciembre de 2016, tan pronto como comenzaron a llegar los exguerrilleros a La Fila, todavía con sus armas al hombro, el panorama era muy distinto. Para encontrarse con ellos el arribo en transporte terrestre presagiaba un difícil trasegar. Los buses llegaban solo hasta un punto y desde allí había que hacer una larga caminata en subida, que incluía sortear pasos fangosos y alambres de púas. La primera impresión era la de adentrarse en el monte para reunirse con los históricos guerrilleros que combatían en la montaña; la constante lluvia ayudaba a ambientar la sensación de estar viendo un documental sobre las FARC-EP. Vestían uniformes nuevos de color verde militar, tenían un corte de pelo soldadesco pero no portaban sus fusiles. Habían adecuado un espacio para 
recibir grupos o individuos visitantes a quienes ofrecían café y comida, y como intercambio quien llegaba allá debía dejarles agua y alimentos.

En este espacio hacían política de principio a fin. Era un gran cambuche hecho de madera y tela verde para cerramiento de construcción, de la misma que usaron para sus viviendas. Montaron residencias rápidas y sencillas con la misma facilidad con que lo hacían en el monte. Mujeres y hombres realizaban las mismas tareas, aquí no se hablaba de diferencias de género, todos se mostraban como un grupo unido. Los comandantes hacían las tareas políticas, y la frase que repetían era que ahora sí iban a contar "su” perspectiva de la guerra y la "verdadera" historia de Colombia.

En un principio eran muy herméticos, los mandos medios no permitían un diálogo directo con los guerrilleros, ni tampoco subir a donde estaban los cambuches, debido a los protocolos establecidos por las Naciones Unidas. Sin embargo, en un momento se pudo acceder y conocer un poco de estos sujetos que dejaban la guerra atrás, pero sin tomar fotografías, puesto que estaba prohibido. Para entonces no podían salir del espacio territorial, cosa que ocurriría cuando entregaran sus armas, lo cual sucedió el 6 de agosto de 2017 (El Nuevo Día, 2017). El proceso de desarme estuvo acompañado por sesenta voluntarios de la ONU, hombres y mujeres principalmente de América Latina, junto a personal militar que hacía parte de la Misión de las Naciones Unidas en Colombia (UNMC). Según el coordinador de voluntarios, Víctor Manuel Velasco, su trabajo buscaba facilitar el diálogo entre comunidades, autoridades locales y las FARC-EP ${ }^{1}$.

1 Dentro de los varios viajes realizados a Icononzo se tuvieron varias conversaciones con representantes de la onU, tanto civiles como militares, quienes hablaron de su experiencia en Colombia. No obstante, al tratar de tener un registro de estas su rechazo era inmediato, ya que esto hacía parte de la política comunicativa de la organización, además, señalaban que el canal debía ser siempre oficial. 
Dentro de los excombatientes de las FARC-EP se podrían reconocer tres tipos de sujetos en la zona de concentración: 1. Los que a pesar de estar uniformados sentían ganas de contar todo lo que vivieron en la guerra, pero eran silenciados por los demás o sus superiores; 2. Aquellos que huían ante la mirada escrutadora de los visitantes, que incluso cubrían sus rostros con pasamontañas o pañoletas, ya que aparentemente seguían viviendo en la guerra y temían lo que vendría después; y 3. Los que rompieron completamente con su tradición militar en la guerrilla, vestían de colores, cambiaron de peinado e inclusive tinturaron sus cabellos: eran hombres y mujeres jóvenes con celulares de última tecnología conociendo un mundo nuevo.

Decir que se visitaba la zona veredal de La Fila generaba la sospecha de los pobladores de Sumapaz y de los militares que custodiaban la entrada al territorio. Las imágenes que se transmitían en la televisión en relación con la barbarie guerrillera, los excesos de la guerra y los miedos de su accionar no iban a cambiar con la firma del Acuerdo de Paz. Muchos todavía siguen pensando que en los ETCR los guerrilleros tienen armas escondidas en caletas y continúan traficando con drogas ilegales. El camino hacia la paz verdadera es largo y tortuoso, y la desconfianza mutua sigue siendo el principal obstáculo.

Hoy sus viviendas han cambiado y actualmente, de lejos, se divisa una ciudadela blanca. Se entregaron $12 \mathrm{~m}^{2}$ a cada excombatiente y algunos terrenos se fusionaron y ampliaron. Son casas pintadas de blanco en honor a la paz; tienen dibujos del "Ché” Guevara, de Fidel Castro, de Manuel Marulanda, de Alfonso Cano, acompañados de sus frases revolucionarias. La bandera de las FARC-EP hondea en varios lugares; a esta se le ha sumado la rosa roja que se convirtió en el logo del partido político creado tras la firma del Acuerdo: Fuerza Alternativa Revolucionaria del Común (FARC), ahora Partido Comunes. Cada vivienda tiene teja de zinc y paredes de asbesto, material dañino para la salud y prohibido en Colombia. Algunos le hicieron patio y balcón, otros le han cambiado 
los pisos y el color de sus paredes interiores, además han comprado muebles. Todas, curiosamente, tienen antenas de los servicios privados de internet y televisión por cable.

El ETCR también cuenta con biblioteca, salón de reuniones, servicio médico y salón de juegos, pero gran parte de sus habitantes pasa el día viajando entre la vereda La Fila y el municipio de Icononzo, donde realizan sus actividades.

Este ha sido el ETCR más visitado por personas e instituciones nacionales y de varios países alrededor del mundo, por su cercanía a Bogotá. Por esta razón han tenido la compañía de sujetos que nunca imaginaron los exguerrilleros: estudiantes de universidades de las principales ciudades del país; periodistas e investigadores europeos, norteamericanos, asiáticos y latinoamericanos, interesados en conocer el proceso de reinserción de primera mano.

Las relaciones que se han establecido entre los excombatientes ubicados en el ETCR Antonio Nariño, de la vereda La Fila, municipio de Icononzo, región del Sumapaz, han sido principalmente comerciales y económicas. Los habitantes de Icononzo prefieren no subir, porque consideran que no hay nada particular que les impulse a hacerlo. En contraposición, el beneficio económico que han recibido ha sido considerable, pues la llegada de este buen número de personas que necesitan abastecerse, más el arribo permanente de visitantes nacionales y extranjeros han generado crecimiento en el número de restaurantes -algunos de comida internacional-, al igual que de los hoteles, establecimientos a los que la afluencia de viajeros les representa un ingreso que antes no percibían. Tiendas de insumos, panaderías, droguerías, bares, discotecas y hasta un pequeño prostíbulo llamado Puerto Amor, ubicado a la salida del pueblo en la vía que conecta con Pandi, dan buena cuenta económica de lo que ha significado el establecimiento de este ETCR en Icononzo. Adicional a esto, a diferencia del miedo que se 
manifestó en Villarrica en cuanto a que la llegada de los excombatientes iba a desacelerar su ya difícil economía, en Icononzo la tierra se ha encarecido, debido a que algunos pensionados, profesores y más que todo bogotanos que quieren tener una casa de campo o una pequeña finca, han adquirido lotes y construido sus viviendas en las cercanías de este municipio.

Por su parte, los excombatientes han desarrollado proyectos productivos para su sostenimiento, que incluyen principalmente procesos agropecuarios, textiles y alimenticios como el de producción de una cerveza artesanal, y también servicios de hospedaje y turismo ecológico, como lo evidenció Marcela Zuluaga en su reportaje de enero de 2019.

\section{Economía solidaria y proyectos productivos}

Como resultado del Acuerdo con el Gobierno colombiano, quedó establecido que este acompañaría a los excombatientes de las FARC-EP financiando proyectos productivos, el tiempo que les permitiera adaptarse a las nuevas dinámicas económicas y de mercado a las que, por obvias razones, no estaban acostumbrados. Por esta razón se creó la organización Economías Sociales del Común (Ecomún), una herramienta para la reincorporación económica colectiva dedicada, por tanto, a asistir planes de economía solidaria.

La implementación del Acuerdo de Paz requería un presupuesto estimado para 2016 de 129,5 billones de pesos. Se estableció igualmente que el Gobierno facilitaría económicamente la reintegración de los exguerrilleros a la vida civil, reincorporación que necesitaba de mucha voluntad política y articulación con los sectores públicos y privados, como lo mostró un estudio de la Fundación Ideas para la Paz en 2019.

Así como se determinó en el punto 3 del Acuerdo, los excombatientes que tuvieran proyectos productivos, individuales o colectivos, recibi- 
rían \$8.000.000 de pesos, por una sola vez, para que los desarrollaran. Estos dineros serían entregados por la onU, gracias al Fondo para la Consolidación de la Paz, que invertiría 3 millones de dólares en este proceso. El ETCR Antonio Nariño es el que más proyectos productivos tiene hasta el momento, a pesar de todas las dificultades que ha generado la falta de acompañamiento del Estado colombiano. Esta es una de las principales críticas de los veedores internacionales de la ONU, ya que para diciembre de 2019 solamente el $18 \%$ de los excombatientes habían recibido estos apoyos a nivel nacional (Misión de Verificación de la ONU en Colombia, 2019).

A pesar de todas estas trabas administrativas y financieras, la ventaja comparativa que tienen los exguerrilleros asentados en el ETCR Antonio Nariño es su cercanía a Bogotá. Al efecto vale resaltar el caso de su producto insignia, la cerveza La Roja, que después de muchos inconvenientes, sobre todo por falta de financiación, continúa su lento paso para convertirse en una opción para los consumidores. De este proyecto hacen parte 30 exguerrilleros y es liderado por Nicolás Hurtado, "Carlos Alberto”, con el acompañamiento de Wally Broderick, colombiano de origen irlandés, profesor de inglés de la Universidad Externado de Colombia, quien les enseñó el proceso de fabricación de una cerveza artesanal.

Las dificultades han sido considerables, más que todo porque los dineros que necesitaron para iniciar la producción de esta cerveza, que inicialmente pensaron llamar La Guerrillera o Marquetalia, por ser el lugar de origen de las FARC, fueron propios, y la búsqueda de inversión y apoyo no ha sido la que esperaban. Por otro lado, está la tortuosa tarea de conseguir los permisos y el registro sanitario que les permita la producción en cadena, al igual que la distribución nacional y la exportación, dentro de una burocracia colombiana que se caracteriza por ser muy lenta. Además, lleva el sello de la guerra, lo que hace que se les cierren las puertas en varios establecimientos y cadenas comerciales, 
pero también, que haga que importe más su procedencia que su sabor, porque quienes la compran señalan que lo hacen porque sienten que con eso apoyan el proceso de reincorporación, como se menciona en el bar Lubianka, ubicado en el barrio Teusaquillo de Bogotá, que decidió apostarle a su comercialización. Los productores de esta cerveza ya cuentan con una cervecería y un bar propio en el barrio 7 de Agosto, localidad de Barrios Unidos, también en Bogotá.

\section{CERVEZA LA ROJA - ETCR ANTONIO NARIÑO}

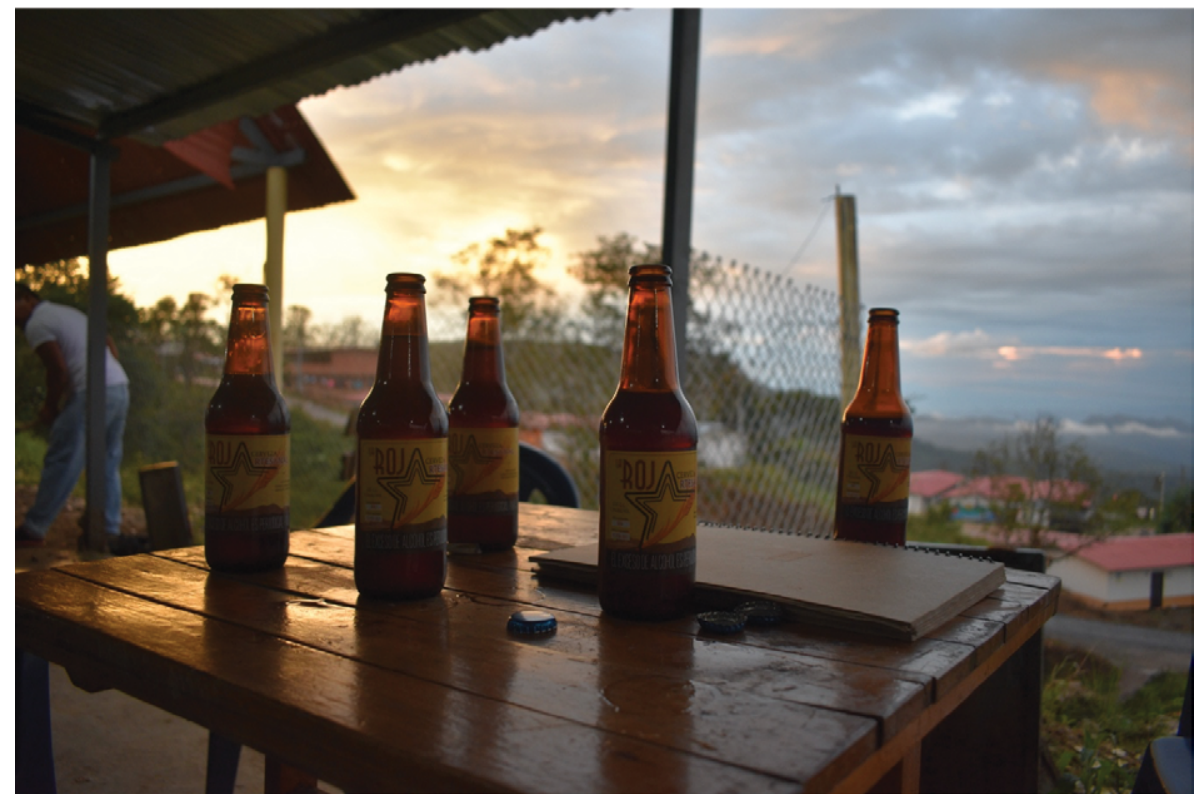

Foto: Wilson Pabón, 7 de junio de 2018.

La necesidad de insertarse en este nuevo sistema económico les generó a los exguerrilleros la obligación de pensar en proyectos sobre todo agrícolas, dado que en gran parte son de extracción rural. Pero esto no les ha funcionado como lo esperaban, debido a las realidades de un mercado que no conocían, al igual que las difíciles condiciones de infraestructura, 
tecnificación y comercialización que sufren los campesinos colombianos (Lefebre y Martínez, 2019, p. 7). Por esto surgieron proyectos nuevos para ellos, como uno de turismo, que incluye un hostal y un restaurante, una asociación deportiva y un taller de confección de kimonos.

Este último hace parte de una cooperativa de 22 personas llamada Tejiendo Paz, proyecto guiado por Ángela Herrera, politóloga de la Universidad Nacional de Colombia, interesada en temas relacionados con los derechos laborales de las costureras, como en el caso de algunos países asiáticos. El gusto por la moda la llevó a crear su empresa ManifiestaHecho en Colombia, que se caracteriza por ser una industria que trabaja con telas nacionales y le apuesta a producir ropa de moda pero hecha sin explotación laboral, como lo manifestó en entrevista.

Luego de año y medio de lanzada Manifiesta-Hecho en Colombia, Ángela Herrera participó en la Primera Brigada del Voluntariado de Paz destinado a las zonas veredales, de la cual hicieron parte estudiantes universitarios de todo el país, acompañando la reincorporación de las FARC-EP, sobre todo en labores de alfabetización, pedagogía de paz y salud (Escobar, 2017). Herrera llegó primero a la ZVTN de Mesetas, en el departamento del Meta, en julio de 2017, y se enfocó en el marketing digital y en el comercio virtual. Su trabajo fue llevado posteriormente al ETCR de Icononzo, ya que allí tenían la cooperativa de textiles, y estableció una alianza solidaria con quienes hacían parte esta. Para ella ha sido un proceso lento pero interesante, ya que venir de la guerra y vivir una vida distinta no era sencillo para los exguerrilleros. De la misma manera, Ángela expresó que es necesario que el sector privado haga parte de este proyecto y lo apoye, al igual que el Gobierno colombiano y organismos internacionales, algo que no se ha podido concretar hasta el momento, como ha sucedido con varios de los proyectos presentados por los excombatientes. 
Ecomún es la cooperativa que acoge los proyectos productivos de los exguerrilleros de las FARC-EP, cuestión abordada en la Estrategia de reincorporación económica y social, del Plan Marco de Implementación del Acuerdo Final, ratificada en el artículo 6 del Decreto Ley 899 de 2017, que habilitó la financiación, asesoría jurídica y técnica para su funcionamiento (Comisión de Seguimiento, Impulso y Verificación del Acuerdo Final, 2018, p. 90). Ecomún tiene un sistema federado, y para marzo de 2020 contaba con 25 planes productivos de emprendimiento de 4960 miembros en todo el país, como lo mencionó Jhonatan Orjuela, director de comercialización de esta organización, quien es el encargado de asesorar, gestionar, acompañar y organizar las formas asociativas de sus afiliados.

\section{COOPERATIVA TEJIENDO PAZ - ETCR ANTONIO NARIÑO}

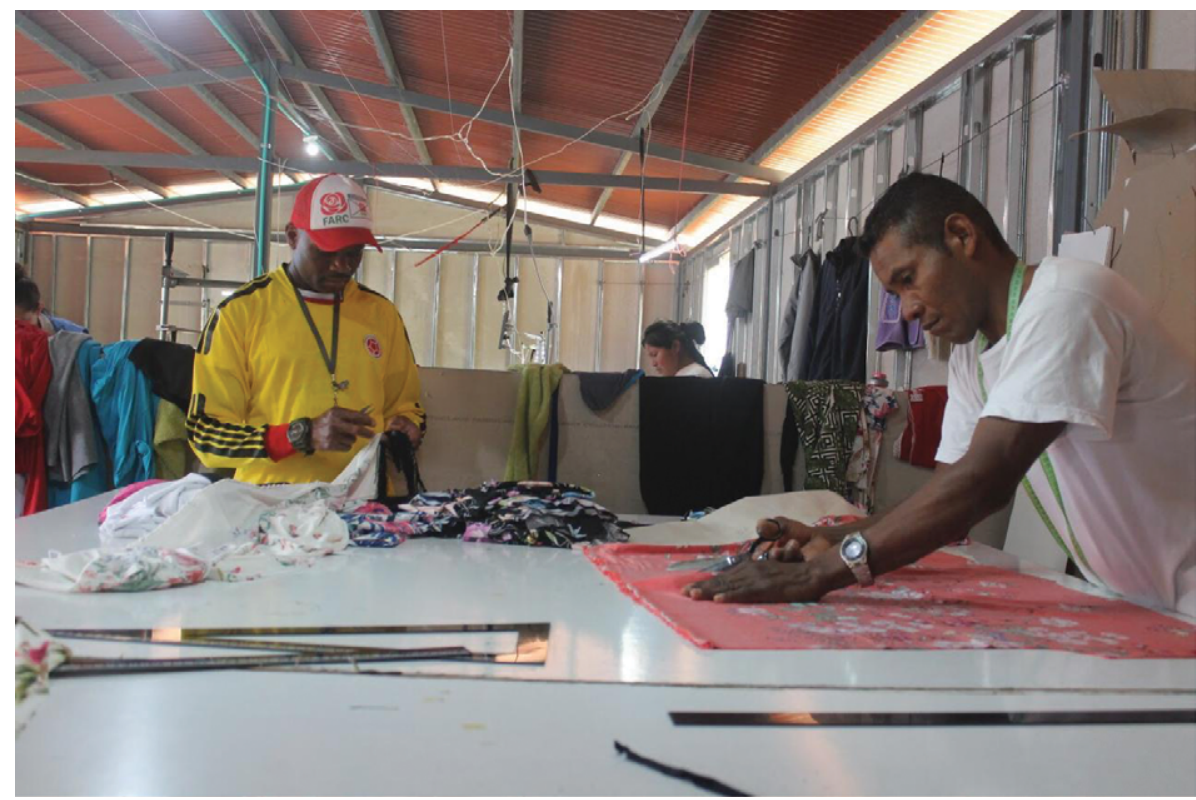

Foto: Ángela Herrera, abril de 2019. 
Según los excombatientes, el incumplimiento de los puntos del Acuerdo de Paz por parte del Gobierno colombiano ha sido recurrente, lo que les ha obligado a gestionar sus proyectos con recursos propios, de familiares, de personas cercanas o de organismos internacionales, por lo que muchos de quienes se acogieron al proceso de paz han decidido mejor dejar los ETCR y dedicarse a otras actividades en su región de origen. Jonathan Orjuela utiliza la siguiente frase en latín para recordarle al Estado que respete su compromiso: Pacta sunt servanda (los acuerdos son para cumplirlos), y además reitera: quienes dejamos las armas "seguimos firmes en nuestro compromiso y respeto por la paz" (Correa Grisales et al, 2020).

A raíz de los problemas de financiación de estas propuestas productivas, evidenciadas en los primeros años de la implementación del Acuerdo de Paz, surge una pregunta que se deberá resolver con una investigación más profunda: ¿Son viables estos proyectos de economía solidaria planteados por los miembros de una guerrilla con enfoque comunista, dentro de la economía de mercado en un mundo neoliberal? Muy pocos han logrado concretarse a nivel nacional, solo lo han hecho aquellos que han contado con apoyo internacional. Queda por ver qué sucederá con la inserción económica de los excombatientes cuando ya no perciban el poco dinero que reciben mensualmente por su desmovilización.

\section{4. "Póngase en mis zapatos"}

Las FARC-EP no tuvieron la posibilidad mediática de dar su versión de porqué habían decidido apostarle a la paz. Solamente ha podido hacerlo el Mando Mayor de esta guerrilla, compuesto por 10 miembros, de los cuales serían 5 senadores y 5 representantes a la Cámara. Gracias a que esto quedó estipulado en el punto 3.2.1.2. Representación política, numeral a. Congreso de la República, del Acuerdo de Paz. estos hacen parte del Congreso por dos periodos consecutivos, desde el viernes 
20 de julio de 2018, y han participado en encuentros políticos y sociales o han sido entrevistados por medios nacionales e internacionales, en donde se ha escuchado su voz y la del grupo que representan.

Cuando comenzó su concentración en las zonas veredales, las FARC determinaron hacer pedagogía con quienes las visitaban. Los encargados de dar cualquier información a grupos y personas eran los mandos medios, sobre todo los políticos, como "Carlos Alberto", cuya oratoria y conocimiento político y literario es destacable entre los demás.

Algunos de ellos también han sido invitados a universidades nacionales, pero no a grandes eventos sino a encuentros y charlas con grupos de estudiantes, quienes los indagan sobre sus años de guerra, sobre el porqué tomaron las armas y porqué las dejaron, y qué esperaban del proceso de paz, del gobierno y de los colombianos. La primera reacción del auditorio es de asombro al darse cuenta de que aquellos con quienes están dialogando son personas con sueños y temores. Esto ha permitido cierta humanización de estos sujetos, señalados como delincuentes y terroristas en los medios de comunicación, principal espacio de comprensión del fenómeno de la guerra en el país a nivel de masas. También han participado en charlas con miembros de las fuerzas militares y de policía, y llama la atención que al finalizar combatientes de uno y otro bando terminaban abrazándose como gesto de paz, por lo menos para 2017 y 2018. Con la llegada del gobierno de Iván Duque esto solo quedó como un recuerdo.

“Jonier Montaños”, excombatiente que participó en 2017 en una charla en la Universidad Autónoma de Colombia, en Bogotá, a la pregunta de un estudiante: ¿Cómo podemos construir paz?, respondió: "Poniéndose en mis zapatos. O sea, sintiendo al otro". Con esto buscaba crear empatía hacia lo que estaban viviendo aquellos que habían estado en el monte durante mucho tiempo, como él, quien se había unido a la guerrilla desde los 16 años. 
De manera oficial, en abril de 2016 se creó la UnIPEP (Unidad Policial para la Edificación de la Paz), que depende de la Dirección General de la Policía Nacional. A través de su Modelo de Construcción de Paz y el proyecto SUMA: Voces y acciones para la convivencia (Policía Nacional, 2019), los policías de esta Unidad acompañan a los exguerrilleros en la realización de acciones de pedagogía del Acuerdo de Paz con las comunidades.

Ahora bien, hay que entender que las FARC-EP eran conscientes de que, como consecuencia de la dejación de armas, iban a perder las relaciones sociales, políticas y económicas que habían construido con las zonas que se encontraban bajo su control. El trabajo netamente político, ahora sin fusiles, iba a ser más difícil indiscutiblemente, ya que el poder de cooptación de las comunidades, a través de las armas, explica el mantenimiento de la guerra, como lo explicó Herfried Münkler (2005), que es una de las condiciones de los conflictos modernos.

Según los miembros de las FARC, las relaciones establecidas entre la guerrilla y las comunidades, que son de vieja data, iban a facilitar estos encuentros. Como menciona "Fernando" frecuentemente, cuando señala que estuvo en algún pueblo de Sumapaz: "Estábamos haciendo política"2. Los encargados de la pedagogía de las FARC, desde que se transformaron en partido político, tienen como función contar los beneficios de la paz y las razones de su desarme. Su proyección es ser sus voceros políticos ante los gobiernos locales, regionales y nacionales, en la defensa de los intereses de campesinos y pobladores urbanos. Su objetivo final: convertir a Colombia en una nación socialista, algo que nunca se perdió de su panorama político, lo que evidencian en sus intervenciones y en su trabajo con las comunidades.

2 En varias conversaciones que no pudieron ser grabadas por solicitud del entrevistado. 


\section{La posverdad sobre la paz}

Al hacer análisis más complejos de las dificultades evidenciadas durante los diálogos de paz entre las FARC-EP y el Gobierno colombiano, hay que entender también el papel jugado por los medios de comunicación en cuanto a la información que transmiten en el país. Los más importantes han permitido el contacto entre la población rural y urbana con el Estado por intermedio de la radio y la televisión, con canales que pertenecen principalmente a grandes grupos empresariales. Pero, además, en los últimos años, ha habido una cobertura cada vez más amplia por medio de los teléfonos inteligentes (smartphones), dispositivos con funciones de teléfono celular y computadora, $\mathrm{y}$ una serie de aplicaciones que facilitan el acceso a redes sociales en las que la verdad se va diluyendo en un mar de información verídica y también engañosa (fake news), dentro de límites muy poco claros. Es aquí donde aparece un nuevo concepto que hay que tener en cuenta para cualquier análisis sobre temas de historia contemporánea y, por ende, de las ciencias sociales: la denominada "posverdad" (Amón, 2016) ${ }^{3}$, que el Diccionario de la lengua española define como: "Distorsión deliberada de una realidad, que manipula creencias y emociones con el fin de influir en la opinión pública y en actitudes sociales."

Se confunde entonces la noticia con la opinión. En los medios de comunicación masiva - prensa, radio y televisión-, han tomado más relevancia las líneas editoriales, los columnistas y los "opinadores" que en muchos casos avalan la invención de todo tipo de noticias, que los investigadores objetivos que han buscado la verdad de la información (Valadier, 2017). Esta versión de posverdad de los hechos es la que circula más fácilmente en las redes sociales, y en Colombia son pocos los trabajos que le han dedicado tiempo a la comprensión de este fenómeno, posiblemente porque es muy reciente y esto ha demorado que se

3 “El 'Diccionario Oxford' entroniza como palabra del año un neologismo que trata de captar la conmoción del ‘Brexit’ o la victoria de Donald Trump” (El País, 2016, p. 1). 
profundice en el debate. Algunas Facultades de Comunicación se han referido al tema, como las de la Universidad Externado de Colombia y la Universidad Eafit de Medellín. De hecho, en el país se habla más de las noticias falsas para deslegitimar información que circula en medios masivos y en redes sociales, que de la problemática de la posverdad en cuanto debate de las ciencias sociales y la historia sobre la posmodernidad y su relación con la subjetividad (Cárcova, 2018).

En este sentido, el proceso de paz entre el Gobierno colombiano y las FARC-EP fue el que más sufrió de este tipo de estrategia mediática en los últimos años, con la que se buscó torpedearlo desde que Juan Manuel Santos decidió sentarse a dialogar con esta guerrilla, situación que se incrementó en el 2016 con la firma del Acuerdo y el plebiscito que pretendía ratificarlo (González, María Fernanda, 2017)4 .

La estrategia de noticias falsas que ha impregnado las campañas políticas a través de los medios masivos (mass media) y las redes sociales, como sucedió durante las elecciones a la presidencia en los Estados Unidos en 2016 y 2020, con el brexit en el Reino Unido, alrededor del mundo en la década del 2010 y en Colombia durante los diálogos en La Habana, la firma del Acuerdo de Paz y su implementación. El miedo, como eje del sentimentalismo que se aplicó a las falsas noticias sobre el proceso de paz, es una característica de los últimos años. Es más, Juan Carlos Vélez Uribe, exsenador y coordinador de uno de los comités que promovieron el voto por el "no", reconoció en una entrevista en el diario La República, en 2016, que utilizaron la indignación como mecanismo de promoción para oponerse al plebiscito por la paz, con una campaña barata y efectiva que buscó, según él "que la gente saliera a votar verraca" (El Universal, 2016).

4 “Social bots, filtros burbuja y fakes: después de una primera etapa en la que internet fue asociada linealmente a los efectos positivos de una mayor participación, hoy comienzan a sopesarse, con menos optimismo, los impactos de la red sobre la política y la democracia” (Nueva Sociedad, 269). 
El temor a que se implantara el modelo comunista con la llegada al poder de representantes de la izquierda y "volvernos como Venezuela", como lo mencionó Iván Duque en su campaña a la presidencia (Moreno, 2018); o la tergiversación por parte de las Iglesias Cristianas de que con la inclusión en el Acuerdo de Paz del enfoque de género — con el que se reconocían los derechos y la participación igualitaria de las mujeres-, se enseñaría el homosexualismo a los niños en escuelas y colegios (Posada, 2019), desviaron la intención de la importancia de lograr la paz, creándole contradictores. A través de algoritmos se inventaron tendencias noticiosas, cuya fuente no importaba al público, pues la verdad se esfumó entre el deseo, el odio y el apego. En definitiva, el sentimiento se ha puesto por encima de la cientificidad (Albright, 2017, p. 89) ${ }^{5}$.

Expresiones como “Farcsantos”, “apátridas”, “guerrilleros disfrazados”, o frases como "si el plebiscito no se aprueba volvemos a la guerra" (CNN Español, 2016), así como tantas otras verdades y mentiras difundidas durante la dificultosa negociación que precedió la firma del Acuerdo de Paz de 2016, y posteriormente para obstaculizar su puesta en marcha, caracterizaron los debates en redes sociales como WhatsApp, Facebook, Twitter e Instagram. Pero también han tenido eco en la opinión pública los medios de comunicación masiva y la política colombiana.

Es difícil saber hasta dónde, individualmente, las noticias falsas influenciaron la decisión de los colombianos al momento de apoyar o no el proceso de paz. Seguramente análisis sociológicos, políticos y también psicológicos ayuden a dilucidar este problema de actualidad. En este sentido, es muy complejo entender igualmente hasta qué punto esta nueva masificación de noticias falsas y verdaderas condicionaron particularmente a los habitantes de Icononzo, pues su percepción de la

5 "The complex ecosystem of emerging platforms, practices, and policies marks the beginning of a new era in the study of media, politics, and information. While the mechanisms are not entirely new, when put together in the scope of global politics and civil discourse, the effects they generate create novel problems." 
política nacional y regional está marcada especialmente por sus vivencias particulares, a las que hay que sumar las sociales, en un pequeño mundo donde la vida nacional se evidencia a través de la paz y la muerte vividas o su recuerdo heredado por generaciones.

\section{Conclusiones}

En Icononzo se ponen de manifiesto, de primera mano, las varias dificultades que ha sorteado la implementación de los distintos puntos del Acuerdo de Paz entre el Gobierno colombiano y la extinta guerrilla de las FARC-EP. El papel estatal, fundamental para garantizar la reconciliación, no ha estado a la altura del momento histórico que vive el país y que la ciudadanía reclama de sus instituciones. El conflicto armado interno de más de setenta años, en el que han estado inmersos los colombianos, ha tenido momentos de guerra y de pacificación, esta última buscada a través de la guerra o del diálogo. Además de la necesidad de una paz real, las causas de los conflictos violentos no han sido atacadas de raíz, y esto generará seguirle sumando años, víctimas y muertos a la larga espiral de violencia vivida en Colombia.

De allí que surja una apremiante necesidad de cambiar la mentalidad política de los colombianos, principalmente en lo que tiene que ver con la manera en que se debe terminar el conflicto armado: de forma pacífica o de manera violenta. La historia muestra que ha prevalecido la segunda sobre la primera, fenómeno que ha sido explicado por la tradición de guerra que ha tenido el país casi que desde su formación, y en las dos últimas décadas por la apuesta de guerra frontal contra las guerrillas que representó el gobierno de Álvaro Uribe Vélez, con Juan Manuel Santos como su ministro de Defensa, y los postulados de su política de Seguridad Democrática, que exaltaba constantemente en los medios de comunicación, y que fundamentó desde tácticas mediáticas muy fuertes hasta la desafortunada estrategia de los llamados "falsos positivos”, que consistió en presentar como subversivos dados de baja 
a inocentes campesinos y a jóvenes pobres de las ciudades con tal de mostrar resultados a la opinión pública ${ }^{6}$. Esta política en realidad lo que hizo fue validar la comisión de crímenes de lesa humanidad por parte de agentes del Estado, en especial por miembros del Ejército, estimulados por el otorgamiento de condecoraciones y premios como vacaciones o bonos salariales. En el marco de esta "seguridad democrática” 6402 colombianos civiles fueron asesinados por el Estado durante el periodo 2002-2008, según la JEP (El Tiempo, 2021).

Esta triste historia de guerra en Colombia no ha terminado aún, ni terminará mientras no haya un proceso de paz completo. La polarización planteada desde los centros de poder es de una política sin matices. Se habla de guerra y paz como si hicieran parte de los discursos de derecha e izquierda, de amigos y enemigos de la reconciliación. Este artículo recoge un estudio de caso sobre cómo se debe materializar la paz y propone que se deben generar las condiciones para que esta sea posible. El problema es que el Acuerdo de Paz de 2016 y sus distintos puntos no se trataron como un fin último o como una necesidad nacional, sino como una condición de la guerra, como si para lograr la paz fuera requisito la victoria militar. Luego de la difícil violencia de los años 2000 se idealizó la paz, pero tal parece que no se sabe qué es ni qué implica volverla realidad.

6 Para entender este fenómeno se recomienda la película de Colbert García Silencio en el paraíso, de 2011. En ella se muestra la manera en que grupos de militares, apoyados por civiles, creaban en zonas periféricas de las ciudades falsas oficinas en las que ofrecían trabajo en el campo, pero en realidad estaban organizadas para llevar jóvenes pobres, en este caso del barrio El Paraíso, en el municipio de Soacha, en los límites con Bogotá, a lugares rurales apartados en otros departamentos. Allí eran disfrazados de guerrilleros y asesinados con tiros de gracia, para luego hacerlos pasar como bajas en combate. Ante las acusaciones al respecto, el expresidente Álvaro Uribe justificó los hechos afirmando: "No fueron a coger café, iban con propósitos delincuenciales y no murieron un día después de su desaparición, sino un mes más tarde” (El Espectador, 2008). 
La paz debe ser un compromiso de todos los colombianos, representados en un Estado que debe volcar sus esfuerzos sobre su consecución. La larga historia del país ha demostrado que la apuesta de guerra no ha sido la mejor estrategia para darle fin a los conflictos, pero algunos grupos políticos se han aprovechado de esta. Además de que un amplio sector sigue pensando en la confrontación armada como única alternativa para acabar con los grupos subversivos o el "enemigo interno", se suma ahora una nueva época más mediática pero menos controlada, lo que ha facilitado minar el interés nacional hacia el logro de una pacificación real. El caso de la desmovilización de las FARC-EP y la ubicación de sus miembros en proceso de reincorporación social en Incononzo (Tolima), se puede exponer al mundo como un claro ejemplo de que la reconciliación sí es posible, a pesar de tantas dificultades, y de que en el país siguen existiendo graves problemas como la inequidad, la corrupción y la violencia. Un gran pacto nacional de transformación permitirá que las próximas generaciones vivan en paz, de forma estable y duradera.

\section{Referencias}

Albright, Jonathan. (2017). Welcome to the Era of Fake News. Media and Communication, 5(2), 87-89. Recuperado de https://www.cogitatiopress.com/ mediaandcommunication/article/view/977/977

Amón, Rubén. (17 de noviembre de 2016). "Posverdad”, palabra del año. El País.

Cárcova, Carlos María. (2018). Acerca del concepto de posverdad. Anamorphosis. Revista Internacional de Direito e Literatura, 4(1), 5-16. Recuperado de http://rdl.org.br/seer/index.php/anamps/article/view/446

CNN Español. (17 de junio de 2016). Santos explica por qué afirmó que si no se aprueba el plebiscito habrá guerra. Recuperado de https://cnnespanol. cnn.com/2016/06/17/santos-explica-por-que-afirmo-que-sino-se-apruebael-plebiscito-habra-guerra/ 
Comisión de Seguimiento, Impulso y Verificación del Acuerdo Final [CSIVI]. (Enero de 2018). Plan Marco de Implementación. Acuerdo final para la terminación del conflicto y la construcción de una Paz estable y duradera. Recuperado de http://extwprlegs1.fao.org/docs/pdf/col191355.pdf

Correa Grisales, Daniela Alejandra; Terán Banquez, Juliana; Pinto Duitama, Karen Yineth y Donato Escobar, Nicolle Sophia. (7 de abril de 2020). Emprendiendo la Paz. Conexión Externado. Recuperado de https://conexion. uexternado.edu.co/emprendiendo-la-paz/

Cosoy, Natalio. (24 de febrero de 2017). 'Baby boom': la ola de embarazos en la guerrilla de las FARC en Colombia. BBC Mundo. Recuperado de https:// www.bbc.com/mundo/noticias-america-latina-39011290

Criollo, Olga Lucía. (30 de abril de 2017). Comerciales en internet, la estrategia con la que las Farc inician su 'batalla' política. El País. Recuperado de https://www.elpais.com.co/proceso-de-paz/comerciales-en-internet-laestrategia-con-la-que-las-farc-inician-su-batalla-politica.html

Defensoría del Pueblo - Colombia. (23 de agosto de 2017). Informe de Riesgo $N^{\circ}$ 039-17 A.I.

El Espectador. (14 de junio de 2020). No los olvidemos. Recuperado de https:// www.elespectador.com/opinion/editorial/no-los-olvidemos/

El Espectador. (15 de abril de 2019). El 96\% de los excombatientes de las Farc le apuestan al emprendimiento. Recuperado de https://www.elespectador.com/colombia-20/paz-y-memoria/el-96-de-los-excombatientes-de-lasfarc-le-apuestan-al-emprendimiento-article/

El Nuevo Día. (15 de agosto de 2017). Planadas e Icononzo dijeron adiós a las armas de las Farc. El Nuevo Día.

El Nuevo Día. (20 de diciembre de 2018). Pierre García es designado Ministro Plenipotenciario ante las Naciones Unidas. Recuperado de https://www. elnuevodia.com.co/nuevodia/actualidad/politica/425750-pierre-garcia-esdesignado-ministro-plenipotenciario-ante-las-naciones-un

El Nuevo Día. (6 de agosto de 2020). Gobierno compró predios de espacio territorial de Icononzo para exFarc. Recuperado de https://www.elnuevodia. com.co/nuevodia/actualidad/politica/452502-gobierno-compro-prediosde-espacio-territorial-de-icononzo-para-exfarc 
El Tiempo. (18 de febrero de 2021). Falsos positivos serían el triple de los reportados por Fiscalía: JEP. Recuperado de https://www.eltiempo.com/ justicia/jep-colombia/falsos-positivos-jep-asegura-que-la-cifra-de-casosseria-6-402-casi-el-triple-de-los-registrados-567774

El Universal. (6 de octubre de 2016). El No ha sido la campaña más barata y efectiva de la historia. Recuperado de https://www.eluniversal.com.co/ colombia/el-no-ha-sido-la-campana-mas-barata-y-mas-efectiva-de-la-historia-237149-EXEU344909

Escobar, María Claudia. (24 de abril de 2017). Brigadas del Voluntariado de Paz. Razón Pública. Recuperado de https://razonpublica.com/ brigadas-del-voluntariado-de-paz/

Fuerzas Militares. (16 de julio de 2016). ¿Conoces los cambios en el uniforme del Ejército de Colombia? Recuperado de https://www.fuerzasmilitares. org/notas/colombia/ejercito-nacional/6956-uniformes-colombia.html

González, María Fernanda. (Mayo-junio de 2017). La «posverdad» en el plebiscito por la paz en Colombia. Nueva Sociedad, (269). Recuperado de https://nuso.org/revista/269/fakepolitica-democracia-y-digitalizacion/

González-Rivera, Juliana. (2017). La información en la era de la posverdad: retos, mea culpas y antídotos. El Eafitense, (112).

Hernández, Douglas. (16 de julio de 2016). ¿Conoces los cambios en el uniforme del Ejército de Colombia? Recuperado de http://www.fuerzasmilitares. org/notas/colombia/ejercito-nacional/6956-uniformes-colombia.html

Jurisdicción Especial para la Paz [JEP]. (19 de abril de 2021). Comunicado 046.

Lefebvre, Iona y Martínez, Harold. (2019). La reincorporación económica de los excombatientes de las FARC. Retos y riesgos a futuro. Bogotá: Fundación Ideas para la Paz.

Londoño Botero, Rocío. (2012). Juan de la Cruz Varela. Sociedad y política en la región de Sumapaz (1902-1984). Bogotá: Universidad Nacional de Colombia.

Memoria Histórica Policial. (s.f.). Recuperado de https://memoriahistoricapolicial.com 
Misión de Verificación de la ONU en Colombia. (26 de diciembre de 2019). Informe del Secretario General de las Naciones Unidas al Consejo de Seguridad. Recuperado de https://colombia.unmissions.org/sites/default/files/ n1942150.pdf

Misión de Verificación de la ONU en Colombia. (8 de marzo de 2019). Gobierno de Colombia, ONU y FARC avanzan en proceso de reincorporación. Recuperado de https://colombia.unmissions.org/ gobierno-de-colombia-onu-y-farc-avanzan-en-proceso-de-reincorporación

Moreno, Juan. (28 de febrero de 2018). "No permitiremos que Colombia se vuelva como Venezuela”: Iván Duque desde el Paseo Bolívar. El Heraldo.

Münkler, Herfried. (2005). Viejas y nuevas guerras. Asimetría y privatización de la violencia. Madrid: Siglo XXI Editores.

Policía Nacional. (18 de agosto de 2019). Voces y acciones para la convivencia, un proyecto que cambia vidas. Recuperado de https://www.policia.gov.co/ noticia/voces-y-acciones-convivencia-proyecto-que-cambia-vidas

Posada Gómez, Diego Bernardo. (2019). La emergencia de la ideología de género ${ }^{\circledR}$ en Colombia: preferir un hijo muerto que marica. Cuadernos de Música, Artes Visuales y Artes Escénicas, 14(2), 75-101.

Real Academia de la Lengua. Posverdad. Recuperado de https://dle.rae.es/ posverdad

Salvado, Antonio; Acerete, Alberto; Fierro, Avelino; Jurado, José María; Zambrano, José Antonio; del Río, Pilar; Navarro, Joan; Oliveira, Rosa; Palacios, Amador; Rello, Mateo; Cañas, Dionisio; Bello, Xuan; Benítez, José Manuel; Neila, Manuel; Gonzalo de Jesús, Patricia; Moutinho, José; Duque, Adriano; Clark, Ben; García, Berta ... Vasco, Rosa. (2017). Periodismo y posverdad: de la perplejidad al escepticismo. Memorias del IX Encuentro Internacional de Periodismo, 2017. Bogotá: Universidad Externado de Colombia.

United Nations Peacemaker. (12 de noviembre de 2016). Acuerdo Final para la terminación del conflicto y la construcción de una paz estable y duradera. Recuperado de https://peacemaker.un.org/node/2924 
Valadier, Paul. (2017). La posverdad, peligro para la democracia. Revista de Fomento Social, 72/2(286), 297-304. Recuperado de https://doi.org/10.32418/ rfs.2017.286.1426

Velasco, Víctor Manuel. (20 de septiembre de 2017). Los Voluntarios de la ONU aceleran el proceso de paz a través de la verificación del alto el fuego, la desmovilización y el desarme en Colombia. Recuperado de https://www. unv.org/es/Success-stories/los-voluntarios-de-la-onu-aceleran-el-procesode-paz-traves-de-la-verificacion-del

Vélez, Juanita. (17 de julio de 2016). En Villarrica no quieren que las Farc regrese. La Silla Vacía. Recuperado de https://lasillavacia.com/historia/ en-villarrica-no-quieren-que-las-farc-regrese-56388

Vicente, Álex. (3 de septiembre de 2018). El 'baby boom' de las guerrilleras. El País. Recuperado de https://elpais.com/cultura/2018/09/02/actualidad/1535883208_623585.html

Zuluaga, Marcela. (25 de enero de 2019). Icononzo: reconstruir después de la guerra. El Turbión. Recuperado de https://elturbion.com/16369

\section{Entrevistas}

“Jonier Montaños” (Bogotá, 20 de septiembre de 2017). Universidad Autónoma de Colombia.

Ángela Herrera (Bogotá, 16 de noviembre de 2019).

Jorge Ortegón, diferentes momentos.

Varias en trabajo de campo, entre 2017 y 2019.

“Valentina Beltrán” (Icononzo, 6 de mayo de 2021). 